\title{
An Assessment of Policy Impact on Agricultural Water Use in the Northeast of Syria
}

\author{
Ahmad Sadiddin \\ Dipartimento di Economia e Politica Agraria \\ Università degli Studi di Napoli Federico II \\ E-mail: asadiddin@gmail.com
}

Received: February 18, 2013 Accepted: March 3, 2013

doi:10.5296/emsd.v2i1.3255 URL: http://dx.doi.org/10.5296/emsd.v2i1.3255

\begin{abstract}
This article aims to measure the impact of the agricultural policy on water use in the northeast of Syria through simulated scenarios to illustrate their potential impacts on achieving some publically desirable objectives such as saving water and maintaining stable farm incomes.

The irrigated agricultural sector in the targeted region is modelled using mathematical programming coupled with farm representation. Farmers' objective is assumed to be the maximisation of expected utility of farm income applied using mean-variance principle. Then the impact of the recent policy reforms is measured, demonstrating that recent reforms are expected to have light impacts on water use and farm income compared to the situation in the reference year.

In light of alternative policy actions, three scenarios are simulated. Modernising the irrigation system scenario illustrates that adoption of modern irrigation techniques by all farms does not restore the hydraulic deficit but has positive impacts on farm incomes. Improving irrigation efficiency scenario leads to increased farm income but fails to sustain any achieved hydraulic balance as some saved water is used to expand irrigated land. The last scenario reveals that the current credit system has negligible effects on cropping patterns and water use in the presence of the current price policy.

These results affirm that price policy is potentially the instrument that affects farmers' decision the most. If effective in stabilizing price for water-saving crops, this may be an important tool to achieve sustainability in water use coupled with improvement in farm welfare.
\end{abstract}

Keywords: Mathematical programming, representative farm types, modern irrigation, credit policy, and price policy 


\section{Introduction}

In Syria, a developing country whose economy is dominated by the agricultural sector and is characterised by a dry and semi-arid climate, irrigated agriculture is a vital component for economic development. Irrigated cultivation produces almost $100 \%$ of summer outputs and some $40-70 \%$ of the winter outputs conditional on rainfall fluctuations. The Government of Syria (GOS), therefore, has implemented numerous interventions to expand irrigated land that has almost doubled since 1985 (NAPC, 2005).

Moreover, for the last two decades Syrian agriculture has been dominated by a few crops considered strategic from the GOS viewpoint; these are primarily wheat, cotton and sugar beet. Of these, wheat is the main food staple for the Syrian population and the GOS has always attempted to maintain a high level of self-sufficiency in this politically sensitive commodity. Cotton is the second main provider of foreign currency (after petroleum). Together with sugar beet and wheat, these crops constitute the main providers of raw materials for a bulk of the public sector factories in a country where the industrial public sector was dominant in Syria until the early 1990s and which still absorbs a substantial proportion of domestic labour force (Westlake, 2001).

The GOS has favoured these three crops for decades, whether through setting floor or fixed producer prices, usually set at levels higher than their international counterparts, or by providing favourable official credit terms. However, since these crops require considerable irrigation to yield acceptable levels of output in the context of the Syrian agro-ecological conditions, they have significantly contributed to the hydraulic deficit problem. Their negative effects on hydraulic balance are obviously observed in the north-east of the Country, especially in Al-Khabour basin (AKB). In this region, water quantity used mainly for agricultural irrigation exceeds that entering the $\mathrm{AKB}$, and so continuously excessive water is drawn from underground stocks (Varela-Ortega \& Sagardoy, 2001).

Given the above, this article aims at assessing the impact of the current policy on the agricultural use of water in the Northeast region of Syria, and to measure the impact of possible changes in the cropping patterns and the irrigation techniques adopted by the farmers as a result of possible policy changes. In addition, one of the predictable side effects for any policy reform is the modification of the exposure to the income risk of farmers. It is therefore critical to evaluate consequences of these risks resulting from any policy reforms in order to gain insights on the political and social acceptance of any policy simulation.

The scope of the paper is confined to the irrigated agricultural sector of the three administrative regions of Deir-Ezzour (DEG), Al-Rakka (RAG), and Al-Hassakeh (HAG), which together comprise the northeast region of Syria (later referred to as DERAHA). This focus is justified by the region's heavy reliance on strategic crops that make them very sensitive to any policy reforms.

\section{Description of the Study Region}

The Mediterranean climate prevails in DERAHA, characterised by rainy winters and dry-hot summers with short autumns and springs. The two largest rivers of Syria run through the area 
of DERAHA, Euphrates and Al-Khabour. These two rivers form the basis of the two hydraulic basins of the region. Al-Khabour basin (AKB) is almost entirely located in HAG, while RAG and DEG are almost entirely located in the Euphrates basin. However, a large area of the latter is located in Aleppo region which is outside the scope of this study (NAPC, 2002).

Available irrigation water is estimated to be equal to 2388 million cubic meters (CMs) in AKB on average, but total irrigation requirements were estimated to be around 3440 million CMs. This means that the actual use is about $40 \%$ higher than the current availability. In the Euphrates basin, water available for irrigation is estimated to be equal to 7470 million CMs on average, while the total requirements account to about 7855 million CMs, about 5\% higher than the availability. These figures question the sustainability of water resources in the region in accordance with present agricultural policy, especially in AKB (GCASR, 2006).

DERAHA includes the largest dam in the country (Euphrates Dam) that has a storage capacity of 14.1 billion CMs and that provides irrigation water to the major part of public irrigation networks present in the region. Meanwhile, the remainder is provided by other small dams on Euphrates River and on Al-Khabour River (NAPC, 2002).

Tables 1 and 2 briefly describe the main characteristics of DERAHA in terms of land use, water sources, and irrigation techniques. Table 1 demonstrates that the irrigated areas count only for $10 \%$ of the total area although they produce the bulk of agricultural output. Considering the three strategic crops that dominate the region's cropping mixes, irrigated area produces $100 \%$ of both cotton and sugar beet outputs and more than $80 \%$ of wheat output (calculated from NAPC database).

Table 1. Land use in DERAHA (2005)

\begin{tabular}{|l|r|r|r|r|r|r|}
\hline Region & $\begin{array}{r}\text { Total area } \\
\text { (thousand } \\
\text { ha) }\end{array}$ & $\begin{array}{r}\text { Cultivated } \\
\text { and Irrigated }\end{array}$ & $\begin{array}{r}\text { Cultivated } \\
\text { (rainfed and } \\
\text { fallow) }\end{array}$ & $\begin{array}{r}\text { Un-cultivate } \\
\text { d, (forests } \\
\text { and steppes) }\end{array}$ & $\begin{array}{r}\text { Building \& } \\
\text { Public } \\
\text { Utilities }\end{array}$ & $\begin{array}{r}\text { Swamps, } \\
\text { lakes, rocky } \\
\text { and sandy } \\
\text { lands }\end{array}$ \\
\hline HAG & 2333 & $18 \%$ & $49 \%$ & $27 \%$ & $4 \%$ & $3 \%$ \\
\hline RAG & 1962 & $10 \%$ & $31 \%$ & $50 \%$ & $3 \%$ & $5 \%$ \\
\hline DEG & 3306 & $5 \%$ & $2 \%$ & $58 \%$ & $1 \%$ & $36 \%$ \\
\hline DERAHA & 7601 & $10 \%$ & $24 \%$ & $46 \%$ & $2 \%$ & $17 \%$ \\
\hline
\end{tabular}

Source: elaborated from NAPC database (www.napcsyr.org)

Table 2 shows the proportions of areas irrigated from the three different sources present in DERAHA, which include private wells, rivers and public networks. The importance of each irrigation source differs from one region to the other. While private wells irrigate more than 83\% in HAG, they are less important in RAG and DEG which irrigate some $39 \%$ in the former and less than $27 \%$ in the latter. Euphrates river is the main source of irrigation water in DEG (+58\%). Although the latter source has some significance in RAG, public networks represent the source most relevant there. 
Table 2. Irrigated land area by irrigation source and technique in DERAHA (2005)

\begin{tabular}{|c|c|c|c|c|c|c|c|}
\hline \multirow[t]{2}{*}{ region } & \multirow{2}{*}{$\begin{array}{r}\text { Total } \\
\text { irrigated } \\
\text { area }(000 \\
\text { ha })\end{array}$} & \multicolumn{3}{|c|}{ Irrigation water source } & \multicolumn{3}{|c|}{ Irrigation techniques } \\
\hline & & $\begin{array}{l}\% \text { irrigated } \\
\text { from wells }\end{array}$ & $\begin{array}{l}\% \text { irrigated } \\
\text { from public } \\
\text { networks }\end{array}$ & $\begin{array}{l}\% \text { irrigated } \\
\text { from rivers }\end{array}$ & $\begin{array}{l}\text { \%irrigated } \\
\text { by flood }\end{array}$ & $\begin{array}{l}\% \text { irrigated } \\
\text { by sprinkler }\end{array}$ & $\begin{array}{r}\% \text { irrigated } \\
\text { by drip }\end{array}$ \\
\hline HAG & 476 & 83.84 & 8.81 & 7.35 & 97.53 & 2.13 & 0.34 \\
\hline RAG & 196 & 37.95 & 40.12 & 21.93 & 99.29 & 0.21 & 0.50 \\
\hline DER & 145 & 26.72 & 15.12 & 58.16 & 97.09 & 2.63 & 0.28 \\
\hline DERAHA & 817 & 62.71 & 17.44 & 19.85 & 97.58 & 2.08 & 0.34 \\
\hline
\end{tabular}

Source: MAAR (2005)

Concerning irrigation techniques that farmers use in DERAHA, Table 2 also demonstrates that although sprinkler and drip techniques are present, they are not relevant. The total area irrigated using these methods did not exceed 3\%. However, the area irrigated by these methods is expected to increase in the near future due to the new irrigation policy (refer to section 4.2.1).

Agriculture is the key income source in DERAHA. Its contribution to households' incomes is higher for those who have access to irrigation, and lower for those who have access to employment opportunities outside the agricultural sector.

Most farms are operated by the owners and their families, but they rely largely on casual labour especially during the picking season of cotton, when large flows of casual labour across the country come to DEHARA region (Wattenbach, 2006). Landless rural people from all over the country are the basic providers of casual agricultural labour, whose organization and mobilization function in accordance with local demand. Traditional contractors perform these functions. They organize labour systems whereby labour demand and supply meet (Forni, 2001).

Livestock production has some importance in DERAHA especially for the poor who rely on it for home consumption to improve the nutritional status of their households, and they rarely sell out their output. Large flocks of sheep and goats are present in DERAHA but are concentrated in the rain-fed areas. Sheep raisers usually use concentrates to feed their flocks or they send them to graze in neighbouring pastures or to join larger flocks that graze in the Syrian steppe.

Table 3. Importance of DERAHA's agriculture in the national context

\begin{tabular}{|l|r|r|r|}
\hline Element & Syria & DERAHA & Share (\%) \\
\hline Total population (thousand inhabitant) & 17921 & 3073 & 17 \\
\hline Rural population* (thousand inhabitant) & 8333 & 1863 & 22 \\
\hline Total area (thousand ha) & 18518 & 7601 & 41 \\
\hline Cultivated area (thousand ha) & 5682 & 2576 & 45 \\
\hline Irrigated area (thousand ha) & 1396 & 764 & 55 \\
\hline Rainfed area (thousand ha) & 4286 & 1812 & 42 \\
\hline Wheat area (thousand ha) & 1668 & 923 & 55 \\
\hline
\end{tabular}




\begin{tabular}{|l|r|r|r|}
\hline Wheat production (thousand ton) & 4041 & 1472 & 58 \\
\hline Cotton area (thousand ha) & 193 & 142 & 73 \\
\hline Cotton production (thousand ton) & 711 & 537 & 76 \\
\hline Sugar beet area (thousand ha) & 28.2 & 8.6 & 31 \\
\hline Sugar beet production (thousand tom) & 1366 & 320 & 23 \\
\hline Area of intercalary crops (thousand ha) & 72 & 59 & 8 \\
\hline
\end{tabular}

* Population is considered rural in Syrian statistics when the population centre has fewer than 20 thousand inhabitants.

Source: elaborated from NAPC database, 2007 (www.napcsyr.org), and the CBS (2006)

DERAHA is a specialised region in the production of the so-called strategic crops, particularly wheat and cotton that currently constitute the main source of farm incomes. These areas produce some $58 \%$ and $76 \%$ of their national outputs, respectively, although the cultivated area of DERAHA does not exceed $45 \%$ of the national figure. Other important crops are maize, barley and sugar beet, which present some $66 \%, 39 \%$ and $23 \%$ of their corresponding national figures, respectively (Table 3). If water is available in summer, farmers grow some intercalary crops such as summer vegetables (tomatoes, cucumber, okra, etc) after harvesting wheat in the same land plot; however, the area of these crops does not exceed 5\% of the total cropped area. Accordingly, the area of the three important strategic crops (wheat, cotton and sugar beet) counts for more than $90 \%$ of the total cropped area (MAAR, 2005).

\section{The Analytical Model}

The choice of mathematical programming models as the analytical tool is based on its potentials to overcome several shortcomings that usually econometric models experience. In agriculture, several crops compete for the available fixed resources, which results in cross effects among the supplies of these crops. This poses the question of having sufficient degrees of freedom in the time-series data used to estimate both the own and cross-price elasticities, which is usually difficult to obtain. This is very much true for developing countries such as Syria, where data of this type, if they exist, are either scarce or quite imprecise. Furthermore, economic structural changes are usually caused by changes in the production technologies, market opportunities, and/or prices of both inputs and outputs. When using econometric models to assess alternative policy options, policy instruments may have to deal with values that are placed outside the values observed historically, which is maybe impossible especially if the policy instrument in question is new (Hazell \& Norton 1986).

Mathematical programming models can assist to solve both problems, since they are based on cross-sectional farm budget data and other information obtained at the micro level to generate optimal cropping mixes and individual supply functions. In addition, they can be used to analyse the direct changes in economic structure whether caused by technology change or by new market opportunities. Furthermore, programming models allow easy and direct estimation of the derived demand functions of inputs such as labour and water. (Hazell \& Norton 1986). 


\subsection{Basic Assumptions}

The analytical model consists of a set of mathematical programming models, one for each farm type. The representative farming models are solved with common vectors of prices to represent the common economic features of DERAHA. However, matrices of technical coefficients are in many cases differentiated to reflect agro-climatic differences across the region.

Each farm type is presumed to maximise the expected utility of its agricultural income given a set of constraints imposed by the availability of land, water, family labour and capital. Other constraints are also imposed by technical conditions (agrarian rotation) or policy intervention (licensing systems of strategic crops). To apply the expected utility theory, we adopt the mean-variance principle, which assumes that the expected utility of farming income can be measured by the certainty equivalent which is, in turn, equal to the expected farming income minus a term that measures income variation (Hazell \& Norton, 1986).

Risks faced by Syrian farmers can be classified under two types: risks associated with markets and those associated with weather. Nevertheless, only price risk is considered, and this is due to the fact that risk associated with natural hazard in Syria is mainly caused by rainfall scarcity and/or fluctuations, which are likely to be minimal in our case since the farms considered are all wholly irrigated.

Expected income is calculated as the farm average net revenue, which is simply the average total revenue minus cash operating costs only. Thus it contains the returns to land, water, family labour, and capital in addition to farm net profits. The costs of land, water, family labour and capital are considered sunk costs and so they do not affect the decision making of farmers. This assumption would be restrictive if markets were perfect for land and labour. However, employment opportunities are always partially or totally precluded to farm family members.

Fixed coefficients are assumed and no economy to scale is considered. Although some farms also have some livestock activities, we omitted them in this model since their relevance for household income is very small (refer to section 2). The model maintains the possibility to hire labour at a given wage rate when available family labour is already exhausted. Farms are also described by their monthly availability of land, family labour, and irrigation water. In addition, irrigation water sources and irrigation techniques are considered essential characteristics of farm structures.

Due to lack of census data at the individual farm level, we assume that all farms rent machinery to perform agricultural operations. This assumption is justified by secondary data sources which show that the proportion of farms owning tractors (taken to be the basic machinery that a farm may possess) in DERAHA relative to the total number of farms did not exceed 3.5\% in 2005, the reference year of the research (MAAR statistical abstracts). In addition, the study survey has uncovered the presence of an active market that provides machinery services at competitive prices through specialised agents. 


\subsection{Farms Classification}

To apply the mathematical programming models, the irrigated farms of DERAHA are classified into relatively few representative farms. Such a classification should take into consideration the following: location, agro-climatic conditions, irrigation technology and sources, farm size, and prevalent cropping patterns that reflect specialisation.

However, due to the lack of census data at the individual farm level, we could not use the last two criteria in the classification, namely farm size and specialisation. Therefore, farms were classified according to their location (mantika, which is the second administrative level in Syria after region), agro-ecological zones (five zones in Syria reflect diverse agro-climatic conditions especially rainfall characteristics), irrigation source (private wells, public networks, or rivers), and irrigation techniques (flood, sprinkler, and drip) (refer to section 3.4). However, we claim that farm size and cropping patterns are implied in our classification because cropping patterns and areas of farms in DERAHA are very similar at the mantika level. We ended up classifying the irrigated farms of DERAHA into 69 representative farm types.

\subsection{Description of the Basic Elements of the Model}

We aim to construct a model that represents the aggregate behaviour of the irrigated farms' sector in DERAHA through a bottom-top approach, that is, to start modelling the behaviour of individual farm types that allows for estimating the cropping areas and the derived demand for water of each individual farm type. Then we obtain the aggregate cropping areas and water demand of the farming sector in the region by calculating a weighted sum of cropping areas and water demand of all individual farm types, in which weights are chosen to represent the relative contribution of each representative farm type to the region's total. These aggregate water demand functions are then used in assessing the incidence of alternative policies on water use. In addition, by assuming that incomes of the farming households generated outside the agricultural sector holds unchanged, farms' gross margins and certainty equivalents are used as indicators of average income and income stability respectively.

The following equations describe the mathematical programming model for each representative farm:

$$
\operatorname{Max} C E=\sum_{j}\left[Q_{j}\left(X_{c, i, w}\right) * E p_{j}-V C_{j}\right]-0.5 R A C\left(\sum_{j} \sum_{k} Q_{j} Q_{k} \sigma_{j k}\right)
$$

Subject to

$$
\begin{gathered}
\sum_{c} \sum_{i} \sum_{w} X_{c, i, w} * \operatorname{Lr}_{c, t} \leq L \\
\sum_{e x} \sum_{i} \sum_{w} X_{e x, i, w} * L r_{e x, t} \leq 0.5 * L \\
\sum_{c} \sum_{i} \sum_{w} X_{c, i, w} * L_{a b r_{c, i, t}} \leq \text { Flab }_{t}+\text { Hlab }_{t} \\
\sum_{c} \sum_{i} \sum_{w} X_{c, i, w} * \text { Watr }_{c, i, t} \leq \text { Wat }_{t}
\end{gathered}
$$


$\sum_{c} \sum_{f} \sum_{i} \sum_{w} \alpha_{c} * X_{c, i, w} * \operatorname{In}_{f, c, i} * P r_{f, c}+\sum_{t} \sum_{c} \sum_{i} \sum_{w} \alpha_{c} * X_{c, i, w} * M p_{c, i, t}+\sum_{c} \sum_{i} \sum_{w} \beta_{c} *$ $X_{c, i, w} * D q_{c, i, w} * D p+\sum_{t} \mathrm{Hlab}_{t} * W h \leq \mathrm{Cap}$

$$
\sum_{i} \sum_{w} X_{s t, i, w} * L r_{s t, t} \leq l i c_{s t} \quad \text { where: } s t \text { (strategic crops) is a subset of c }
$$

Where:

$C E$ : is the measure adopted for the expected utility of farm income and it is assumed to be the certainty equivalent of the corresponding expected farm income (SP).

$Q_{j}$ : is the total output of the $j$-th product $(\mathrm{kg})$

$E p_{j}:$ is the expected price of $j$-th product (SP)

$\sigma_{j k}$ : is the covariance of prices of the $j$-th and $k$-th products (SP)

$V C_{j}$ : is variable costs of the $J$-th product (SP), composed of variable inputs costs (fertilisers, chemicals, packing materials, etc), pumping costs (diesel, oil and maintenance), rented machinery costs (tillage, seeding, harvesting, etc), hired labour costs, and credit costs.

$R A C$ : is the absolute risk aversion coefficient.

$X_{c, i, w}$ : is the level of cropping activity to be chosen in the optimal solution, it represents the area of $c$-th crop irrigated by the $i$-th irrigation technique and the $w$-th irrigation source (ha).

$L$ : is the farm size (ha)

$F l a b_{t}$ : is family labour availability in the $t$-th month (hour/month)

Hlabt: is the amount of labour hired in the $t$-th month (hour)

$W a t_{t}$ : is irrigation water availability in the $t$-th month $(\mathrm{CM} /$ month)

$\alpha_{c}$ : is the coefficient of cash anticipation for the $c$-th cropping activity applied for inputs whose costs are financed by the official credit system (\%).

$\beta_{c}$ : is the coefficient of cash anticipation for the $c$-th cropping activity applied for inputs whose costs are not financed by the official credit system (\%).

$L r_{c, t}:$ the unit requirements of land for the $c$-th cropping activity in the $t$-th month (ha/month). It is a dummy variable that takes the value of 1 when the crop is present and zero otherwise.

Watr $_{c, i t}:$ are the unit requirements of irrigation water for the $c$-th cropping activity and the $i$-th irrigation technique in the $t$-th month $(\mathrm{CM} / \mathrm{ha} /$ month).

$\operatorname{Labr}_{c, i, t}$ : are the unit requirements of labour for the $c$-th cropping activity and the $i$-th irrigation technique in the $t$-th month (hour/ha/month). 
$I n_{f, c, i}:$ are the unit requirements of physical inputs namely seeds, fertilisers and other chemicals for the $f$-th input, $c$-th cropping activity and $i$-th irrigation technique $(\mathrm{kg} / \mathrm{ha})$

$M p_{c, i, t}:$ are the unit costs of rented machinery for the $c$-th cropping activity, the $i$-th irrigation technique and the $t$-th month (SP/ha).

$\operatorname{Pr}_{f, c}$ : defines the price of $f$-th input used for $c$-th cropping activity (SP/unit (kg e.g.)).

$D q_{c, i, w}$ : are the unit requirements of diesel necessary for pumping irrigation water for $c$-th cropping activity, $i$-th irrigation technique and $w$-th irrigation source (litre/ha).

$D_{p}$ : price of diesel input which is unique and set centrally by the GOS (SP/litre).

Wh: is the wage rate for hired labour (SP/hour).

Cap: is cash availability at the beginning of the agricultural year (SP)

lic $c_{s t}$ : defines the maximum area that can be cultivated with cotton or sugar beet for each farm according to the licensing system (ha).

Equation (1), taken in its general form from Hardaker et al. (2004), represents the objective function to be maximised, which is composed of two parts. The first one explains the expected farm income, which is calculated as the sum over the $j$-the product for the quantity produced multiplied by the relevant expected price minus the relevant variable costs, while the second part explains the risk premium, calculated as the income variance of the farm multiplied by the risk aversion coefficient and by 0.5 .

Equations from (2) to (7) describe the technical constraints of the model. Some of these constraints are related to the limited availability of a resource, while others are related to the technical aspects of the representative farm type. Equation (2) states that the total area occupied by all cropping activities in a certain month must not exceed the total farm size. Equation (3) describes the constraint imposed by agronomic rotation pursued by farmers, as there is a group of crops (lentil, chickpea, broad bean, sugar beet, cumin, peanut, cotton, and potato) that should not be cultivated in the same land plot two subsequent times; otherwise pests and diseases will grow and output will fall. Therefore, the total area occupied by these crops in each month must not exceed $50 \%$ of the total farm size.

Equation (4) states that the total labour use in each month must not exceed the total availability of family labour in that month plus a term $\left(\mathrm{Hlab}_{t}\right)$ that allows the hiring of additional labour if needed. Equation (5) describes the constraint related to the availability of irrigation water, so that total water use in a month must not exceed water availability in that month.

Equation (6) attempts to capture some aspects of cash capital constraint although it cannot be described as representing fully such a constraint. The best way to model the cash capital constraint would be through a set of inequalities in which one for each month or season represents all financial inflows and outflows of the representative family farm, and which 
takes into account all kinds of credit. However, such way of modelling requires a very detailed data on farm cash flows that are not available and are too expensive to collect. Nevertheless, equation (6) enables us to incorporate the liquidity problem that farmers face and to evaluate the possible impact that the current credit policy has on the decision making of farmers. It is believed that farmers may prefer to grow strategic crops because they would face binding credit constraints if they grew other crops. As the current official credit system is biased in favour of the so-called strategic crops, it is of interest to model this bias and to measure the effect of eliminating it.

The equation simply states that the total amount of cash capital needed to finance the purchases of inputs and the agricultural operations must not exceed the amount of cash capital available at the beginning of the agricultural year. As shown, the four terms of the equation left-hand-side represent the four elements of the explicit production costs (physical and other costs, machinery costs, diesel costs, and hired labour costs respectively), each multiplied by a set of coefficients that we call "coefficients of cash anticipation". These coefficients are calculated by dividing the length of the biological cycle for each cropping activity in months over 12; the total number of the months in the year. Therefore, crops with longer biological cycles are associated with higher values for the coefficients of cash anticipation.

The coefficients are classified in two groups and, in which the values of the coefficients for most crops are identical. These groups differ only in terms of the coefficients' values, which are associated with strategic crops for the physical inputs as well as rented machinery whose costs are financeable by the credit system. For these two elements associated with the set of coefficients, the values associated with cotton, wheat, sugar beet and barley are all equal to zero, meaning that farmers entitled to grow these four crops are less constrained by the availability of cash since a significant part of their production costs can be funded by the official credit system.

This implies that farmers, when faced with two crops, would prefer to grow one with a shorter cycle, if the two crops were able to generate the same profit. However, if one of these two crops belongs to the strategic crops group but the other does not, then farmers will grow the strategic one since most of its production costs can be funded by the official credit system.

Equation (7) describes constraints imposed by policy interventions. It states the maximum area that can be cultivated with cotton or sugar beet in each representative farm, since farmers in Syria have to respect these quotas should they have to get the supported price for these two crops.

\subsection{Data Sources}

The data used in the farms' classification are available in the database of the National Agricultural Policy Center (NAPC: www.napcsyr.org) and the Statistical Abstracts of the Ministry of Agricultural and Agrarian Reform (MAAR 2005). Many technical coefficients 
and other parameters are also drawn from these two sources although others are adopted from other sources and from an ad hoc survey.

The detailed description of farm classification process as well as data used in constructing the mathematical programming model for each farm type is provided in Appendix I.

\subsection{Solving and Validating the Model}

Using mathematical programming as a predictive tool requires validating and calibrating the model. Prediction can only be reliable when the model can replicate the observed data that demonstrate farmers' choices.

The software used in setting up, solving, calibrating and simulating our mathematical programming model is the General Algebraic Modelling System (GAMS).

Two kinds of observed data are used as references to validate the model: cropping patterns at the individual farm type level and water use at the region and the hydraulic basin level. The validation aims to get the results of the optimal solutions on cropping patterns and water use as close as possible to their observed counterparts. The parameter used to achieve this purpose is the risk aversion coefficient, which is assumed to reflect farmers' attitudes towards risk, the higher the coefficient, the more risk averse the farmer.

Of several methods proposed in the relevant literature for estimating risk aversion coefficient, here we adopt the one proposed by McCarl and Spreen. It is based on estimating the risk aversion coefficient such that the difference between the observed behaviour and the optimal solution is minimised. This requires solving the model for each farm for several values of risk aversion coefficient, and then we choose the value that gives the cropping mix closest to the observed one.

The second step of validating the model is to check if cropping areas and water use produced by the model are consistent with their observed counterparts at the level of each individual region. Here some slight modifications are made on irrigation requirements to guarantee that the amount of water use produced by the model is close enough to that of the observed data.

Table 4. Comparison between observed data and model results for key variables

\begin{tabular}{|c|c|c|c|}
\hline & Observed data & Solution & $\%$ difference \\
\hline \multicolumn{4}{|c|}{ Water use (million CM) } \\
\hline HAG & 3440 & 3595 & +4.51 \\
\hline RAG & 3119 & 3146 & +0.87 \\
\hline DEG & 2374 & 2369 & -0.21 \\
\hline \multicolumn{4}{|c|}{ Wheat area (ha) } \\
\hline $\mathrm{HAG}$ & 344500 & 341408 & -0.90 \\
\hline RAG & 132627 & 135729 & +2.34 \\
\hline DEG & 101648 & 106822 & +5.09 \\
\hline \multicolumn{4}{|c|}{ Cotton area (ha) } \\
\hline HAG & 85412 & 87447 & +2.38 \\
\hline
\end{tabular}




\begin{tabular}{|c|c|c|c|c|}
\hline RAG & 58959 & 60147 & \multicolumn{2}{|l|}{+2.01} \\
\hline DEG & 25943 & 25106 & \multicolumn{2}{|l|}{-3.23} \\
\hline \multicolumn{5}{|c|}{ Sugar beet area (ha) } \\
\hline RAG & 4750 & 4958 & \multicolumn{2}{|l|}{+4.38} \\
\hline DEG & 4338 & 4132 & \multicolumn{2}{|l|}{-4.75} \\
\hline \multicolumn{5}{|c|}{ Area of intercalary crops (ha) } \\
\hline $\mathrm{HAG}$ & 3332 & 3441 & \multicolumn{2}{|l|}{+3.27} \\
\hline RAG & 15919 & 15664 & \multicolumn{2}{|l|}{-1.60} \\
\hline DEG & 39318 & 41448 & \multicolumn{2}{|l|}{+5.42} \\
\hline \multicolumn{5}{|c|}{ Area of other winter crops (ha) } \\
\hline HAG & 13414 & 13396 & \multicolumn{2}{|l|}{-0.13} \\
\hline RAG & 4001 & 3848 & \multicolumn{2}{|l|}{-3.82} \\
\hline DEG & 6260 & 6515 & \multicolumn{2}{|l|}{+4.07} \\
\hline \multicolumn{5}{|c|}{ Total cropped area (ha) } \\
\hline HAG & 445094 & 445693 & \multicolumn{2}{|l|}{+0.01} \\
\hline RAG & 219951 & 220347 & \multicolumn{2}{|l|}{+0.18} \\
\hline DEG & 183954 & 184024 & \multicolumn{2}{|l|}{+0.04} \\
\hline \multicolumn{5}{|c|}{ Range of calibrated risk aversion coefficients } \\
\hline HAG & \multicolumn{4}{|c|}{$0.001-0.005$} \\
\hline RAG & \multicolumn{4}{|c|}{$0.002-0.007$} \\
\hline DEG & \multicolumn{4}{|c|}{$0.001-0.004$} \\
\hline \multicolumn{4}{|c|}{$\begin{array}{l}\text { Coefficient of correlation }(\mathrm{CC}) \text { between risk aversion coefficient and farm size in all } \\
\text { DERAHA }\end{array}$} & -0.60 \\
\hline \multicolumn{5}{|c|}{\begin{tabular}{l|l}
$\mathrm{CC}$ between risk aversion coefficient and farm size in all DERAHA except DEG & -0.80 \\
\end{tabular}} \\
\hline
\end{tabular}

Source: the study results, NAPC database, and GCASR (2006)

Table 4 summarises the differences between observed data and the solution results at the region level for water use and areas of most important crops. To make the comparison easier, we assemble crops that occupy small areas in two groups according to their similarities and differences in terms of technical aspects and market conditions. The group of intercalary crops, which include maize, sesame, watermelon, soybean, eggplant and tomato, are all summer crops that are grown in the short season after wheat harvest in the same land plot. The group of other winter crops, on the other hand, includes all other winter crops which are: barley, peanut, lentil, chickpea, cumin, and spring potato, which are usually grown in the January-June period. Table 4 shows that differences in water use and cropping patterns are very small and that they can be neglected.

The lowest part of Table 4 represents the ranges of values that the absolute risk aversion coefficients take in the three regions. According to the Expected Utility Theory, the value of an absolute risk aversion coefficient increases as risk aversion increases. In addition, the theory predicts that risk aversion decreases as wealth increases. Here we test for this by calculating the coefficient of correlation between the values of risk aversion coefficient and the farm size that is considered to be an indicator of wealth. The corresponding coefficient of 
correlation for all DERAHA is equal to $-60 \%$ as shown in the table, which already illustrates a negative and high correlation between the two parameters along with the prediction of the Expected Utility Theory. However, the findings of the study survey, enhanced by the findings of other studies (Wattenbach, 2006), emphasises the high importance of off-farm and non-agricultural income for farmers of DEG where average farm size is relatively very small. Calculating the coefficient of correlation after excluding the values associated with the DEG farm types gives the value of $-80 \%$, which illustrates a very high correlation. In DEG instead, farm holding size cannot be used an indicator of wellbeing since it generates only about $35-40 \%$ of the total households' income (Wattenbach, 2006). This may explain the relatively low values of risk aversion coefficient found for farming systems of this region as illustrated in Table 4.

\section{Results and Discussion}

Due to large number of farm types (69), the discussion is kept at the region level. Therefore, we use the sum of individual gross margins (GMs) and certainty equivalents (CEs) at the region level to indicate changes in income level and income stability. Then we use the coefficient of variation (CV) of the GMs and CEs for each individual region to shed light on the impact of any policy simulation on equity. However, due to the importance of hydraulic deficit in $\mathrm{AKB}$, we demonstrate the impact of any simulation on water deficit in $\mathrm{AKB}$ separately.

The first scenario is the measurement of the possible impact of the policy reforms that took place after the reference year of the study (2005). So we compare the base year results with the new baseline results of 2009, which will be later referred to as the reform baseline. Other scenarios are then performed starting from the reform baseline.

\subsection{Impacts of Policy Reforms Undertaken after the Reference Year (2005)}

Starting from 2005, the GOS has undertaken a series of reforms on many aspects of the agricultural policy, namely credit policy, pricing policy of inputs and outputs as well as the subsidy system of certain crops. Official interest rate for short term credit was increased from $6 \%$ to $8.5 \%$ per year in 2005 . In 2008 , the GOS has substantially reduced the subsidy on diesel price so its effective price has almost doubled two times (from 7.5 to $21 \mathrm{SP} /$ litre).

Following the increase of diesel price, the GOS undertook a series of actions aiming at compensating the farmers for the increased costs of production resulting from the rise of diesel price. Consequently, the prices of strategic crops were raised (wheat: from 12 to 20 SP/kg, barley: from 9 to $16 \mathrm{SP} / \mathrm{kg}$, cotton: from 30.75 to $41 \mathrm{SP} / \mathrm{kg}$ and sugar beet: from 2.25 to $3.75 \mathrm{SP} / \mathrm{kg}$ ). In addition, a subsidy of 30 thousand SP/ha is given to producers of cotton irrigated from private wells. In addition, the new reforms added maize to the group of strategic crops and determined for it a floor price equal to $16 \mathrm{SP} / \mathrm{kg}$. Furthermore, prices of chemical fertilisers have been recently subject to noticeable increase as a result of one further step towards the "liberalisation" of the agricultural sector in Syria (nitrogen fertiliser: from 9 to $18 \mathrm{SP} / \mathrm{kg}$, phosphate fertiliser: from 9 to $23.9 \mathrm{SP} / \mathrm{kg}$, and potash fertiliser: from 13 to 57.2 $\mathrm{SP} / \mathrm{kg})$. 
Table 5. The 2005 baseline results versus reform baseline for cropping mixes and water use

\begin{tabular}{|c|c|c|c|}
\hline & 2005 baseline results & Reform baseline results & $\%$ change \\
\hline \multicolumn{4}{|c|}{ Water use (million CM) } \\
\hline HAG & 3595 & 3575 & $-0,56$ \\
\hline RAG & 3146 & 3391 & 7.79 \\
\hline DEG & 2369 & 2473 & 4.39 \\
\hline \multicolumn{4}{|c|}{ Wheat area (ha) } \\
\hline HAG & 341408 & 341933 & 0.15 \\
\hline RAG & 135729 & 134983 & -0.55 \\
\hline DEG & 106822 & 109578 & 2.58 \\
\hline \multicolumn{4}{|c|}{ Cotton area (ha) } \\
\hline HAG & 87447 & 87447 & 0.00 \\
\hline RAG & 60147 & 60148 & 0.00 \\
\hline DEG & 25106 & 22906 & -8.76 \\
\hline \multicolumn{4}{|c|}{ Sugar beet area (ha) } \\
\hline RAG & 4958 & 4958 & 0.00 \\
\hline DEG & 4132 & 3701 & -10.43 \\
\hline \multicolumn{4}{|c|}{ Maize area (ha) } \\
\hline HAG & 0 & 398 & Undefined \\
\hline RAG & 12067 & 30092 & 149.37 \\
\hline DEG & 36213 & 39498 & 9.07 \\
\hline \multicolumn{4}{|c|}{ Intercalary crops area (ha) } \\
\hline HAG & 3441 & 2871 & -16.56 \\
\hline RAG & 3597 & 1963 & -45.43 \\
\hline DEG & 5234 & 13987 & 167.23 \\
\hline \multicolumn{4}{|c|}{ Other winter crops area (ha) } \\
\hline HAG & 13396 & 12872 & -3.91 \\
\hline RAG & 3848 & 4594 & 19.39 \\
\hline DEG & 6515 & 6189 & -5.00 \\
\hline
\end{tabular}

Having selected new effective prices, we deflated them using the wholesale price index calculated by the Syrian Central Bureau of Statistics (CBS) to erase inflation. Taking 2005 as a base year, the wholesale price index was 1.32 in 2010 suggesting $32 \%$ of inflation for wholesale prices. We use the wholesale price index for deflation as the wholesale market level determines the effective price for producers.

Table 5 compares the 2005 base year results with the reform baseline results for cropping patterns and water use at the region level. We follow the same assemblage for crops that occupy minor areas as presented in Table IV, but we separate maize from the group of intercalary crops to see the impact of the policy reforms on its area, since recent reforms added maize to the group of strategic crops and set a floor price for it.

Table 5 demonstrates that maize area increases in all regions, while intercalary crops' area decreases in HAG and RAG but increases significantly in DEG. Setting floor price for maize 
has a positive impact on its cultivated area as expected. Changes in areas of wheat, cotton, sugar beet and other winter crops are not large. Noticeable only is the decrease of cotton area in DEG which is maybe due to the fact that cotton is very demanding in terms of variable inputs, especially diesel whose price was subject to an elevated increase.

Noticeable is the increase of water use in RAG and DEG reflecting the overall increase of the cropping area in these two regions, while it remains somehow stable in HAG (Table 5).

At AKB level, Table 6 shows that although hydraulic balance improves slightly after the reforms, a large deficit is still present, and the saved water accounts only to 20 million CMs, which is less than $1 \%$ of the used water.

Table 6. Foreseen impact of policy reform on water use and balance in AKB

\begin{tabular}{|l|r|}
\hline Water availability (million CM) & 2388 \\
\hline Water use before reform (million CM) & 3595 \\
\hline Water use after reform (million CM) & 3575 \\
\hline Water balance before reform (million CM) & -1207 \\
\hline Water balance after reform (million CM) & -1187 \\
\hline Water saved (million CM) & 20 \\
\hline
\end{tabular}

Source: study results, GCASR (2006)

Table 7 shows that the impact of the policy reforms on income is generally positive although obvious differences exist among regions. Impact on total income and income stability is negligible in HAG, while the table reveals improvement in average income and income stability in both RAG and DEG. The overall improvements in income are mainly due to the expansion of maize cultivation whose price has been recently stabilised.

Table 7 also reports the coefficient of variation (CV) of average income and income stability among individual farm types. The results show that, at the level of the entire region, income distribution tends to become less equitable (increased CV). However, the changes in CV are different from one region to the other; while they are positive in HAG and DEG, they are negative in RAG. This illustrates a fall in income equity in the former but an increase in the latter. Therefore, although the new policy reforms promote average income and income stability in DEHARA taken altogether, they promote income equity only in RAG.

Table 7. Foreseen impact of policy reform on employment and income in DERAHA

\begin{tabular}{|c|c|c|c|c|}
\hline Region & HAG & RAG & DEG & total DERAHA \\
\hline \multicolumn{5}{|c|}{ Sum of Gross Margins (million SP) } \\
\hline $\begin{array}{l}2005 \text { baseline } \\
\text { results }\end{array}$ & 12976 & 8794 & 5994 & 27763 \\
\hline $\begin{array}{l}\text { reform baseline } \\
\text { results }\end{array}$ & 13402 & 9780 & 6916 & 30098 \\
\hline$\%$ change & $+3.29 \%$ & $+11.22 \%$ & $+15.38 \%$ & $+8.41 \%$ \\
\hline \multicolumn{5}{|c|}{ Coefficient of variation of Gross margins among individual representative farms } \\
\hline baseline & 0.53 & 0.41 & 0.18 & 0.67 \\
\hline
\end{tabular}




\begin{tabular}{|l|l|l|l|l|}
\hline results & & & & \\
\hline $\begin{array}{l}\text { reform baseline } \\
\text { results }\end{array}$ & 0.55 & 0.39 & 0.20 & 0.67 \\
\hline$\%$ change & $+2.85 \%$ & $-4.02 \%$ & $+15.26 \%$ & $+0.20 \%$ \\
\hline \begin{tabular}{l} 
Sum of Certainty Equivalents (million SP) \\
\hline $\begin{array}{l}2005 \\
\text { results }\end{array}$
\end{tabular} & 8590 & 5509 & 26894 \\
\hline $\begin{array}{l}\text { reform baseline } \\
\text { results }\end{array}$ & 12795 & 9710 & 6558 & 29529 \\
\hline $\begin{array}{l}\% \text { change } \\
\text { Coefficient of variation of Certainty Equivalents among individual representative farms }\end{array}$ & +3261 & 0.42 & 0.18 & 0.68 \\
\hline $\begin{array}{l}2005 \\
\text { results }\end{array}$ & 0.54 & 0.40 & 0.20 & 0.68 \\
\hline $\begin{array}{l}\text { reform baseline } \\
\text { results }\end{array}$ & 0.55 & $-5.10 \%$ & $+9.02 \%$ & $-0.39 \%$ \\
\hline \begin{tabular}{l}
$\%$ change \\
\hline
\end{tabular}
\end{tabular}

Source: study results

\subsection{Simulation of New Alternative Policies}

Many alternative policy scenarios can be simulated after reaching the new (reform) baseline, but they cannot all be covered and discussed in this paper. Here we choose a few scenarios that we consider the most important. These are: the modernisation of the irrigation systems at the farm level, improving irrigation efficiency at the farm level, and eliminating the bias of the credit system that currently favours strategic crops. The rationale of choosing each of these scenarios is presented in the relevant contexts below.

Before moving to discuss these scenarios in detail, a word must be said on the validity of the reform baseline results. At the time of writing, no official data has been released on cropping patterns in the region following the implementation of reforms implemented. Nevertheless, all qualitative information available up to now through our network of contacts in the region affirm that maize area has expanded extensively due to the new policy, which is in line with the predictions of our model.

\subsubsection{Impact of Modernising the Irrigation Systems}

As a response to the problem of water deficit, the GOS launched, in 2005, the National Project for the Conversion to Modern Irrigation, aiming to convert all irrigated areas of the Country to drip and sprinkler techniques. The Project works through offering favourable credit terms, namely by zero-interest loans and repayment period of ten years. In addition, the fund contributes up to $20-35 \%$ of the up-front costs as a subsidy. Later on, the GOS declared that conversion to modern irrigation is obligatory and all farmers will have access to the credit, since even personal collateral became accepted. Priorities are given to areas where water problem is critical such as the AKB basin. 
The scenario then aims to assess the impacts of converting irrigation technique from flood to drip and sprinkler in all farms. In the model we deal with the costs of conversion to these irrigation techniques as sunk costs, since farmers pay for the networks only once at the outset, but we deal with the associated expenses as variable costs and they are accounted for in the model using appropriate parameters.

Table 8. Impact of conversion to modern irrigation on water use and cropping patterns

\begin{tabular}{|c|c|c|c|}
\hline & reform baseline & $\begin{array}{r}\text { Conversion to modern } \\
\text { irrigation }\end{array}$ & $\%$ change \\
\hline \multicolumn{4}{|c|}{ Water use (million CM) } \\
\hline HAG & 3575 & 3213 & -10.13 \\
\hline RAG & 3391 & 3063 & -9.66 \\
\hline DEG & 2473 & 2301 & -6.97 \\
\hline \multicolumn{4}{|c|}{ Wheat area (ha) } \\
\hline HAG & 341933 & 342116 & +0.05 \\
\hline RAG & 134983 & 136154 & +0.87 \\
\hline DEG & 109578 & 108923 & -0.60 \\
\hline \multicolumn{4}{|c|}{ Cotton area (ha) } \\
\hline HAG & 87447 & 87447 & +0.00 \\
\hline RAG & 60148 & 60148 & +0.00 \\
\hline DEG & 22906 & 25106 & +9.60 \\
\hline \multicolumn{4}{|c|}{ Sugar beet area (ha) } \\
\hline RAG & 4958 & 4687 & -5.46 \\
\hline DEG & 3701 & 3992 & +7.87 \\
\hline \multicolumn{4}{|c|}{ Maize area (ha) } \\
\hline HAG & 398 & 6776 & +1602.53 \\
\hline RAG & 30092 & 42584 & +41.51 \\
\hline DEG & 39498 & 46986 & +18.96 \\
\hline \multicolumn{4}{|c|}{ Intercalary crops area (ha) } \\
\hline HAG & 2871 & 2973 & +3.56 \\
\hline RAG & 1963 & 2220 & +13.11 \\
\hline DEG & 13987 & 13967 & -0.14 \\
\hline \multicolumn{4}{|c|}{ Other winter crop area (ha) } \\
\hline HAG & 12872 & 12689 & -1.42 \\
\hline RAG & 4594 & 4408 & -4.05 \\
\hline DEG & 6189 & 6104 & -1.37 \\
\hline
\end{tabular}

Source: study results

Although sprinkler irrigation is suitable for all crops, drip is preferred for some crops such as cotton and summer vegetables (tomato and cucumber e.g.). On the other hand, some crops, such as wheat and barley, cannot be irrigated by drip irrigation. Table 8 illustrates the potential impact of the conversion on water use and cropping patterns in DERAHA.

The only important changes in cropping patterns are the increases in maize area in all DERAHA, especially in HAG, decreases in areas of the group of other winter crops in RAG as well as increases of intercalary crops area in RAG. Obviously, the increases of yields (due 
to better utilisation of inputs under the modern techniques as the local experts assert) are behind the increases in the area of some crops.

The quantity of water saved is relatively small due to two reasons: the first is technical since we assume a relatively low irrigation efficiency (sprinkler irrigation saves 10\%, while drip irrigation saves $20 \%$ of water use in comparison with the traditional flood method) based on the experience of local experts. In addition, our model predicts that a portion of the water saved by the adoption of modern irrigation is being used to expand the irrigated area that was not possible before since water constraints was a limiting factor.

Table 9. Impact of conversion to modern irrigation on water use and balance in AKB

\begin{tabular}{|l|r|}
\hline Water availability (million CM) & 2388 \\
\hline Water use of reform baseline (million CM) & 3575 \\
\hline Water use after conversion to modern irrigation (million CM) & 3213 \\
\hline Water balance after reform (million CM) & -1187 \\
\hline Water balance after conversion to modern irrigation (million CM) & -825 \\
\hline Water saved after conversion to modern irrigation (million CM) & 362 \\
\hline
\end{tabular}

Source: study results

Table 10. Impact of conversion to modern irrigation on employment and income

\begin{tabular}{|c|c|c|c|c|}
\hline Region & HAG & RAG & DEG & total DERAHA \\
\hline \multicolumn{5}{|l|}{ Sum of Gross Margins (million SP) } \\
\hline Reform baseline & 13402 & 9780 & 6916 & 30098 \\
\hline Conversion to modern irrigation & 17650 & 12320 & 8807 & 38778 \\
\hline$\%$ change & $+31.70 \%$ & $+25.98 \%$ & $+27.35 \%$ & $+28.84 \%$ \\
\hline \multicolumn{5}{|c|}{ Coefficient of variation of Gross margins at farms' level } \\
\hline Reform baseline & 0.55 & 0.39 & 0.20 & 0.67 \\
\hline Conversion to modern irrigation & 0.50 & 0.38 & 0.20 & 0.62 \\
\hline$\%$ change & $-8.30 \%$ & $-1.97 \%$ & $-1.85 \%$ & $-8.23 \%$ \\
\hline \multicolumn{5}{|c|}{ Sum of Certainty Equivalents (million SP) } \\
\hline Reform baseline & 13261.0 & 9710.0 & 6558.0 & 29529.0 \\
\hline Conversion to modern irrigation & 17481.6 & 12238.0 & 8354.4 & 38074.0 \\
\hline$\%$ change & $+31.83 \%$ & $+26.04 \%$ & $+27.39 \%$ & $+28.94 \%$ \\
\hline \multicolumn{5}{|c|}{ Coefficient of variation of Certainty Equivalents at farms' level } \\
\hline Reform baseline & 0.55 & 0.40 & 0.20 & 0.68 \\
\hline Conversion to modern irrigation & 0.51 & 0.39 & 0.19 & 0.68 \\
\hline$\%$ change & $-8.40 \%$ & $-2.38 \%$ & $-2.58 \%$ & $-8.32 \%$ \\
\hline
\end{tabular}

Source: study results

At the level of $\mathrm{AKB}$, the amount of water saved is noticeable (more than 10\%); however, there remains a significant deficit of more than 800 million CM (Table 9), duplicating the results of a past study (Varela-Ortega and Sagardoy 2001), stating that given the current farm level efficiency of modern irrigation, the latter cannot solve the problem of water deficit in $\mathrm{AKB}$, and therefore, a change in the cropping patterns may be inevitable if water deficit is to be reversed. 


\section{Mll Macrothink}

Environmental Management and Sustainable Development9292

ISSN 2164-7682

2013, Vol. 2, No. 1

The impact of conversion to modern irrigation is positive generally on agricultural incomes and their stability, which is caused by reduced pumping costs and increased yields. This is shown clearly in Table 10, which also illustrates a more equitable distribution of income (negative changes in $\mathrm{CVs}$ ).

\subsubsection{Impact of Improving Modern Irrigation Efficiency}

Previous studies demonstrate the existence of technical, environmental, and educational constraints that limit the efficiency of modern irrigation. These constraints relate to different soil quality, different types and qualities of irrigation networks, and lack of know-how amongst farmers in using modern irrigation techniques effectively (NAPC, 2005). Therefore, even if full compliance is realised within the time horizon of policy implementation ( 5 years starting form 2009), it is unrealistic to assume full benefit if the policy implementation if this is not coupled with intensive extension services, which is the challenge of the new policy.

In this sub-scenario, we assume a gradual increase in the efficiency of modern irrigation that would be the consequence of removing one or more of these constraints over time. We assume that the GOS incurs the costs associated with this improvement in irrigation efficiency as it is part of the new irrigation policy; therefore, we do not account for them in our study.

Increasing irrigation efficiency is performed by a gradual increment in the value of an efficiency parameter. Therefore, when the efficiency parameter has the value of zero, it corresponds to the current efficiency, while when it takes the value of 0.5 , it corresponds to an increase in irrigation efficiency equal to $100 \%$, implying that irrigation requirements and pumping costs of all crops are reduced to half, since the relationship between water consumption and pumping costs is very close to be linear in our case.

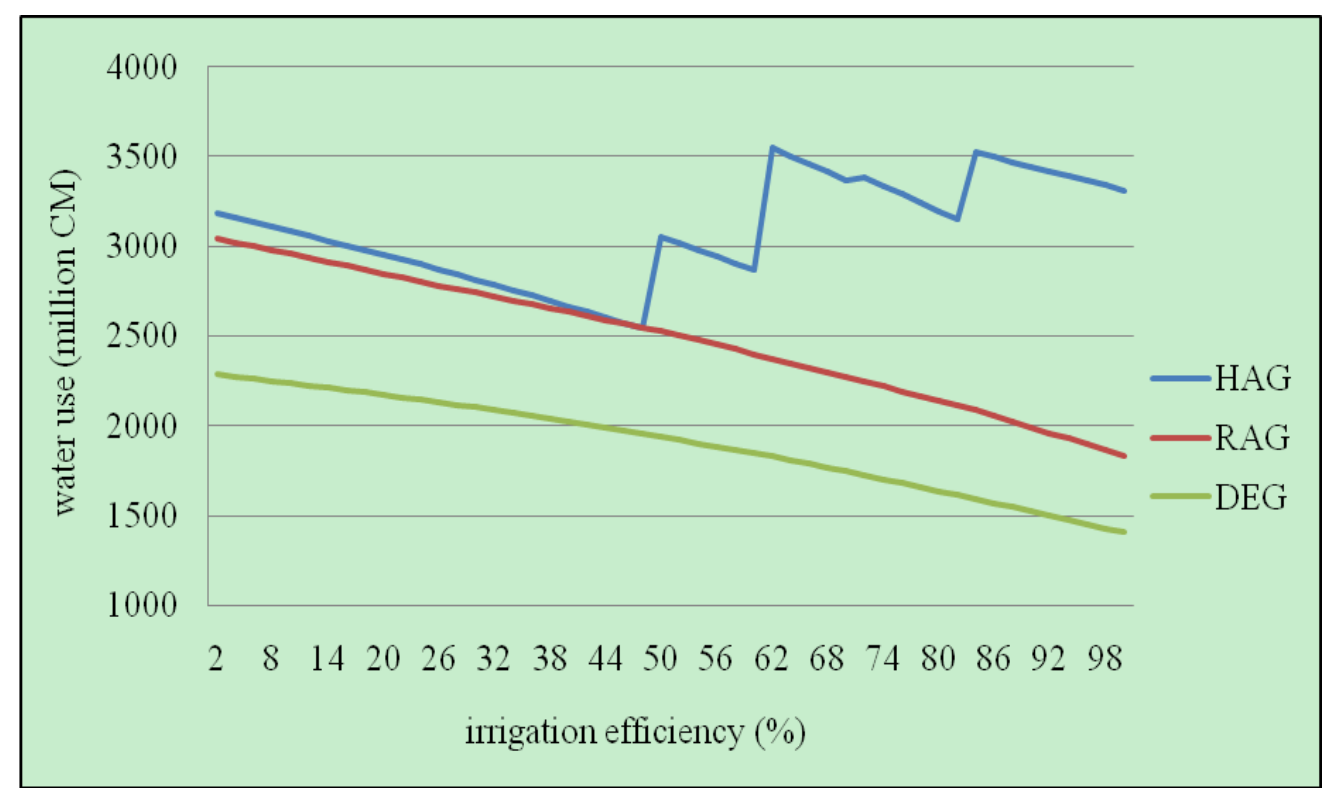

Figure 1. Impact of improving modern irrigation efficiency on water use

Source: study results 


\section{MInstitute Macrothink $^{\text {Int }}$}

Environmental Management and Sustainable Development9393

ISSN 2164-7682

2013, Vol. 2, No. 1

Figure 1 traces the impact of improving irrigation efficiency on water use in the three regions of DERAHA. All regions witness a gradual decrease in water use at the beginning. At higher levels of efficiency, however, HAG witnesses an increased trend in water use that persists even when irrigation efficiency reaches $100 \%$.

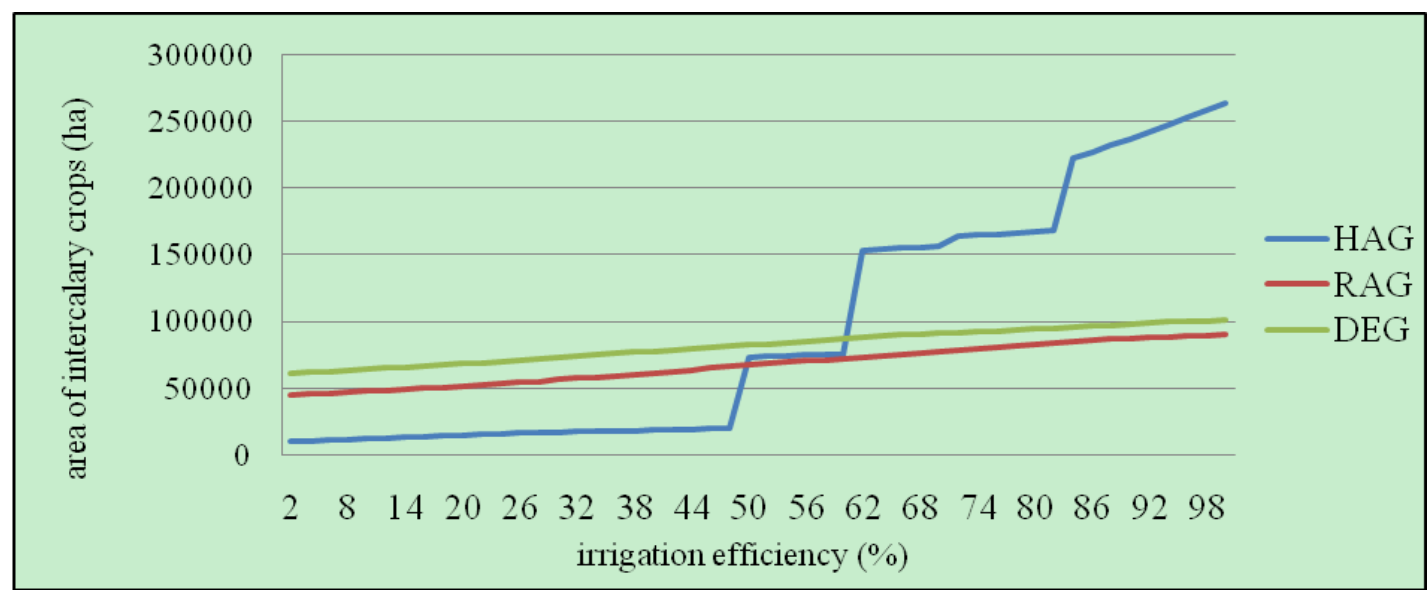

Figure 2. Impact of improving irrigation efficiency on area of intercalary crops

Source: study results

The seemingly strange impact in HAG is explained by the fact that water saved by increasing irrigation efficiency gets used to expand the cultivation of some intercalary crops, namely maize. These crops are not cultivated in large areas under low levels of irrigation efficiency mainly due to the binding irrigation constraint, but also due to high pumping costs that make such crops much less remunerable in HAG. As irrigation efficiency increases, the available water becomes sufficient to irrigate extra areas and the pumping cost of a unit of water is decreased. Figure 2 traces the impact of increasing irrigation efficiency on the areas of intercalary crops grown in the three regions. It illustrates that although the areas of intercalary crops go up in the three regions, their increase is considerable only in HAG.

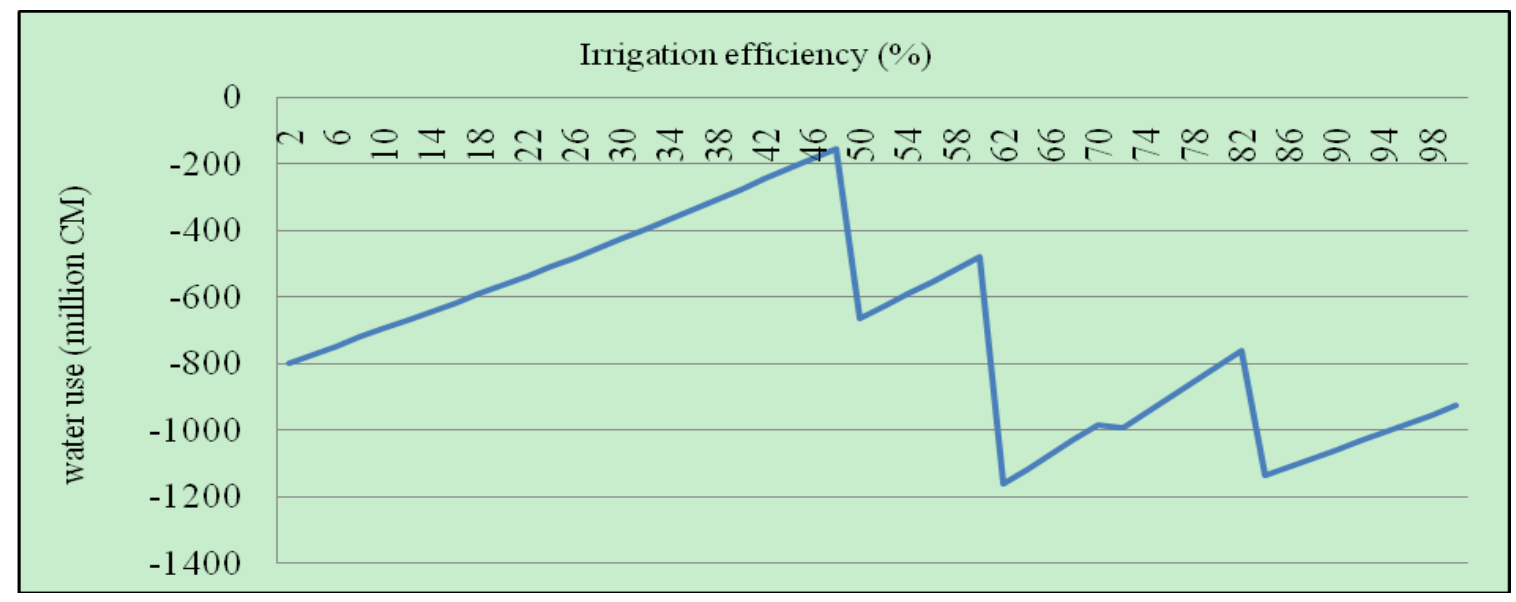

Figure 3. Impact of improving irrigation efficiency on water balance in AKB

Source: study results 


\section{Mll Macrothink}

Environmental Management and Sustainable Development9494

ISSN 2164-7682

2013, Vol. 2, No. 1

This result has an implication for the most efficient way to solve the water problem in AKB. Figure 3 shows how water deficit approaches zero at efficiency levels of about 50\%, but then it goes up steadily. This points out that modernising the irrigation system may not suffice to restore water balance in $\mathrm{AKB}$ basin, in which there may be a need to impose some restriction on summer cropping.

\subsubsection{Impact of credit provision on a per-hectare basis decoupled from crops}

This scenario aims at measuring the impact of eliminating the bias in the credit policy that favours now the strategic crops. This scenario allows providing credit on the basis of the total farm size and not in function of cultivated crops. To perform this scenario, the coefficients of $\alpha_{c}$ associated with expenses fundable by the official credit system are replaced by coefficients of $\beta_{c}$. This is equivalent to say that no credit is provided for specific crops or specific inputs. Then, equation (6) is modified to become as follows:

$$
\begin{aligned}
& \sum_{c} \sum_{f} \sum_{i} \sum_{w} \alpha_{c} * X_{c, i, w} * I n_{f, c, i} * P r_{f, c}+\sum_{t} \sum_{c} \sum_{i} \sum_{w} \alpha_{c} * X_{c, i, w} * M p_{c, i, t}+\sum_{c} \sum_{i} \sum_{w} \beta_{c} * \\
& X_{c, i, w} * D q_{c, i, w} * D p+\sum_{t} H l a b_{t} * W h \leq \operatorname{Cap}+L * C d t *(1+I r)
\end{aligned}
$$

Where:

$C d t$ : is the amount assumed to be available per hectare from the ACB at the official interest rate $I r$, while all other parameters of the equation are defined before.

The figure associated with the parameter $C d t$ is calculated by dividing the total amount of credit available to the region in question, and currently provided only to strategic crops, by the number of hectares in the region.

Table 11. Impact of eliminating credit policy distortion on water use and cropping patterns

\begin{tabular}{|l|r|r|r|}
\hline & reform baseline & $\begin{array}{r}\text { New credit policy } \\
\text { scenario }\end{array}$ & change \\
\hline Water use (Million CM) & 9439 & 9445 & $0.06 \%$ \\
\hline Wheat area (ha) & 586494 & 587526 & $0.18 \%$ \\
\hline Cotton area (ha) & 170501 & 170498 & $0.00 \%$ \\
\hline Sugar beet area (ha) & 8659 & 8659 & $0.00 \%$ \\
\hline Maize area (ha) & 69988 & 69988 & $0.00 \%$ \\
\hline Intercalary crops area (ha) & 18821 & 19129 & $1.61 \%$ \\
\hline Other winter crops area (ha) & 23655 & 22626 & $-4.55 \%$ \\
\hline
\end{tabular}

Source: study results

Table 11 illustrates the impact of this scenario on water use and cropping patterns in the entire region of DERAHA. The most important observation is that the impact is negligible both cropping patterns and water use. The only noticeable changes are for the areas of intercalary crops and other winter crops, in which the former increases by $1.6 \%$ while the latter decreases by $4.55 \%$. However, we can easily neglect these changes knowing that the 
combined area of these two groups of crops accounts only for less than $5 \%$ of the total cropped area.

Knowing that the impact of this simulated policy is negligible on cropping patterns and water use, we can conclude that it is so also for income. This conclusion allows us to infer that the current credit policy, although it favours strategic crops, has a very limited effect on farmers' decision in the presence of the pricing policy that heavily favours strategic crops.

\section{Conclusions}

Agricultural policy in Syria continues to strive to achieve several contradictory objectives through compromising sets of policy instruments. The main objectives of the agricultural policy as defined in the Syrian Agricultural Strategy for the period 2001-2010 concern, at the same time, improving farmers' incomes, increasing self-sufficiency of basic staple foodstuffs and conserving scarce natural resources, namely water (NAPC, 2006). According to this strategy, the GOS has been using mainly the pricing policy to achieve the first and the second objectives, while very little had been done to achieve the objective related to water conservation. On the contrary, there was a period in which, farmers were encouraged to use water irrationally through a random digging of wells to expand irrigated cultivation (NAPC, 2005).

However, the GOS recently declared a national plan to convert all irrigated areas in the Country to modern irrigation as a consequence of increased awareness on the issue of water scarcity in the Country. In the meantime, several suggestions have been made to change the structure of current cropping patterns in the Country in an attempt to switch some areas from water-intensive crops to others with lower irrigation requirements. Nevertheless, the question of impact of such structural changes on farmers' incomes and their stability remains legitimate, whether such changes are caused by modernising the irrigation system, modifying the current cropping patterns, or any combination of both.

A mathematical programming model using the Expected Utility Theory applied through mean-variance principle, combined with a set of representative farms, is used to estimate farm incomes and water use under different conditions in DEHARA. In particular, the reference year results are compared to the results of a new baseline which takes into account all policy reforms that have taken place in the period following 2005 . Then this new baseline (reform baseline) is used to simulate new possible alternative policies. Those policies which are considered in this paper are (1) the impact of modernising the irrigation system, (2) improving the irrigation efficiency, and (3) decoupling agricultural short-term credit from strategic crops.

\subsection{Summary of Major Results}

The comparison between the baseline results of 2005 and the reform baseline results shows that recent reforms are expected to have a limited impact on water use and farm income. Water use is reduced by less than 5\% in the entire region, but increases in income level and stability are more noticeable in the three regions. It is of interest to mention that the policy 
measure that has the most significant impact is the stabilisation of maize prices that caused an expansion of its cultivated area after the reforms.

Moreover, the results of other alternative policy scenarios reveal several interesting policy implications that are not obvious at first glance. They illustrate that adoption of modern irrigation techniques by all farms of the region does not solve the hydraulic deficit in AKB, where there would still be a deficit of more than eight hundred CMs due to two factors: first, the present efficiency of modern irrigation techniques at the farm level is very low compared to that in research stations. Second, water saved by the adoption of modern irrigation may be used to expand irrigated land. The latter observation is plainly observed in HAG where current intercalary cropping is constrained by the scarcity of irrigation water. As irrigation efficiency increases, per unit irrigation costs also decline and then a major part of the water saved gets used to expand irrigated cultivation of intercalary crops.

In addition, the model results allow us to evaluate the effectiveness of various public policy instruments, and to reveal which of them affect the decision-making of farmers the most. They show that decoupling the official credit provided by the ACB from strategic crops would have negligible effects on cropping patterns and water use consequently, in the presence of the current pricing policy of the strategic crops. Consequently, the model results affirm that it is price policy that is potentially the instrument that has the most notable affect on the farmers' decision-making. Therefore, if the GOS is effective in stabilizing prices for water saving crops, this may be an important tool to combine sustainable water use with improvement in farm welfare.

\subsection{Merits and Limitations of the Study}

The first limitation of the study is that the analytical model used in this study needs a large amount of data, which limits its applicability for individual researchers unless they have access to census data or at least they have resources to conduct a large ad hoc survey. Conducting such studies without having sufficient data detailed at the farm level forces researchers to rely on ad hoc assumptions about values of technical parameters that may be unrealistic, and in order to calibrate the model results on the observed behaviour they may have to impose further assumptions without a scientific basis.

In addition, our model, in its current design, does not allow us to assess the costs of the proposed alternative policies, which limits our ability to make precise recommendations, as the cost of any policy is a very important element and a new policy is only justified if its benefits overweigh its costs. Furthermore, the model has a comparatively static nature and fails to capture the dynamics of reality with respect to the interaction between supply and demand and so we cannot analyse scenarios that simulate withdrawal of state intervention from the agricultural sector.

In addition, the way the matrixes of technical coefficients are modelled imply that farmers know in advance the yields to be harvested and the level of inputs to be applied regardless of the impact of subsequent events that may motivate farmers to change their production plans during the agricultural season. The way prices of agricultural products are modelled imply 
that farmers are aware of the assumed state of nature and of the values that prices take in each of them with the associated probability, which is a very strong assumption to accept.

However, this does not mean that the model is far from being representative of the farming sector of DERAHA. It is acceptable to assume that farmers try to maximise profits but they are conditioned by risky and uncertain environment. Therefore, given the amount and the types of data available, we believe that our model is the best way to capture the basic elements of the agricultural irrigated sector in DERAHA taking into consideration the component of risk and uncertainty. As we mentioned right above, the model helps to reveal policy implications that are not evident, as it gives us clear hints as to how to solve problems with conflicting objectives such as reducing water use without penalising farmers' incomes.

The history of agricultural policy in Syria generally and in DERAHA particularly requires us to assume exogenous prices. The main strategic crops (wheat, cotton and sugar beet) that occupy the bulk of irrigated area in DERAHA have been subject to heavy state intervention for decades, which prevents private enterprises from involvement in these three commodities. Production and marketing activities for these commodities has been entirely manipulated by the state.

One other merit of such models is that they encourage and assist the modellers to think comprehensively and deeply about the technical aspects of farm management, that is a very important issue in the field of applied economics. Learning technical details is an essential key to understand farmers' behaviour, which improves modelling skills and produces more reliable results.

\subsection{Suggestions for Future Research}

Some of the limitations highlighted above can be overcome by further improvements of the analytical model. The costs of the alternative proposed policy can be included in the model by adjusting the latter to take into account multiple objective functions, when the relevant data is available with an acceptable degree of reliability. This means transforming the model to a sectoral structure as explained in Hazell \& Norton (1986), in which a set of constraints of government budgetary resources is introduced.

However, the model in its present structure can be used for conducting further research. Many possible policy scenarios can be tested, from which we only did four, which we currently consider the most important. However, other scenarios might be interesting in the future depending on the conditions of relevant commodity markets at the international level. Scenarios including the changing prices of some strategic crops such as wheat and cotton may be interesting if prices of these commodities change significantly at the world market. Scenarios on stabilising prices of some promising crops can be also performed, especially those with low irrigation requirements such as cumin. Pricing of irrigation water might also be a policy scenario aiming at reducing water use although it is politically sensitive and maybe currently unfeasible, but things may change in the future.

In addition, the model can be also used to conduct joint scenarios, modernising the irrigation system while stabilising cumin price is one example. Another interesting example maybe 


\section{Ml Macrothink}

Environmental Management and Sustainable Development 9898

ISSN 2164-7682

2013, Vol. 2, No. 1

abolishing the subsidy linked to cotton irrigated from wells and introducing a new subsidy system in which the latter is linked to some policy objectives such as reducing summer cropping for the sake of saving water. Another kind of scenario could be to look at the introduction of new crops that may assist in realising some policy preferences such as saving irrigation water; however, the technical parameters of these crops must be known with high precision in order to obtain reliable results.

\section{Acknowledgements}

The accomplishment of this paper required a collection of massive data, both primary and secondary. For this, I would like to thank all people and institutions that provided me the necessary help and assistance during data collection stages, which are the National Agricultural Policy Center (NAPC) in Damascus, the Departments of Agriculture and Agrarian Reform in Al-Hassakeh, Deir-Ezzour and Al-Rakka regions in Syria, and the General Commission for Agricultural Scientific Research in Damascus.

The main research activities were carried out as parts of my Ph.D activities at the University of Naples Federico II, may not have been accomplished without the great support that I received from Dr. Carlo Cafiero who was not only my advisor but was also a personal friend in all aspects. Carlo has accompanied my work on this article from the initial phase of setting up the mathematical programming model used in the analysis to the final delivery of the paper. To him I express grand gratitude, respect and compassion.

\section{Acronym and definitions}

ACB Agricultural Cooperative Bank

AKB Al-Khabour basin

CBS Central Bureau of Statistics

CE certainty equivalent

$\mathrm{CM} \quad$ cubic meter

$\mathrm{CV} \quad$ coefficient of variation

DEG Deir-Ezzour region

DERAHA The entire region of Deir-Ezzoour, Al-Rakka, and Al-Hassakeh

GCASR General Commission for Agricultural Scientific Research

GM gross margin

GOS Government of Syria

HAG Al-Hassakeh region

MAAR Ministry of Agriculture and Agrarian Reform 
Mantika

Second administrative level after region in Syria; literally it means province or district

MOI

Ministry of Irrigation

NAPC

National Agricultural Policy Center

RAG

Al-Rakka region

\section{References}

CBS. (2006). Total results and characteristics of population and households. Results of the 2004 national census conducted in 2004 by the Syrian Central Bureau of Statistics (CBS).

Forni, N. (2001). Land tenure systems: structural features and policies. FAO Project GCP/SYR/006/ITA, the National Agricultural Policy Centre (NAPC), Damascus, 69, [online] available: http://www.napcsyr.org/dwnld-files/policy_studies/en/08_land_tenure_en.pdf

GCASR. (2006). The Annual Abstract of Water Requirements of the Agricultural Plan. General Commission for Agricultural Scientific Research Damascus (GCASR), 329 pp (in Arabic).

Hardaker, J.B., Huirne, R.B.M., Anderson, J.R., \& Lien, G. (2004). Coping with Risk in Agriculture, second edition. CABI Publishing, 333 pp. p.105-110.

Hazell P. B. R., \& Norton R. D. (1986). Mathematical Programming for Economic Analysis in Agriculture. MacMillan Publishing Co., New York, 400 pp. p.4-6. p.80 and p.135-163.

Kenneth. \& Judd. (1998). Numerical Methods in Economics. Massachusetts Institute for Technology, the USA, Library of Congress Cataloging-in-Publication Data. p.257-266.

MAAR. (2005). Land Use Balance, The Ministry of Agriculture and Agrarian Reform (MAAR), the Department of Statistics and Planning, Damascus 74 pp (in Arabic).

MAAR. (1994). National Farm Data Handbook. Ministry of Agriculture and Agrarian Reform (MAAR), Damascus 86 pp (in Arabic).

MAAR Statistical Abstracts. Reports issued by the Ministry of Agriculture and Agrarian Reform on an annual basis (in Arabic).

McCarl, A. B., \& Spreen, T. H. (without publishing year). Applied mathematical programming using algebraic systems. Without publishing house, available online: http://agecon2.tamu.edu/people/faculty/mccarl-bruce/mccspr/thebook.pdf. p.7-14.

NAPC. (2006). Mid-term review of Syrian Agricultural Strategy. National Agricultural Policy Center (NAPC), Damascus, $110 \mathrm{pp}, \quad$ [online] available: http://www.napcsyr.org/dwnld-files/policy_studies/en/20_midterm_sy_agr_strategy_en.pdf. p.19. 


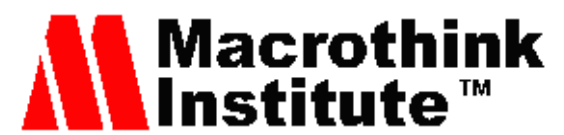

Environmental Management and Sustainable Development 100100 ISSN 2164-7682

NAPC. (2005). Economic incentives and policy options for sustainable water use in agriculture: the case of Al-Khabour basin, Syria. National Agricultural Policy Center (NAPC), Damascus, 82 pp. p.i, p.79 and p.75.

NAPC. (2002). The state of food and agriculture in the Syrian Arab Republic. National Agricultrual Policy Center (NAPC), Damascus, $86 \mathrm{pp,} \mathrm{[online]} \mathrm{available:}$ http://www.napcsyr.org/dwnld-files/periodical_reports/en/sofas_2002_en.pdf.p.15 and p.11.

Varela-Ortega, C., \& Sagardoy, J.A. (2001). Agricultural water use. FAO Project GCP/SYR/006/ITA, the National Agricultural Policy Centre (NAPC), Damascus, $150 \mathrm{pp}$, [online] available: http://www.napcsyr.org/dwnld-files/policy_studies/en/11_water_en.pdf. p.18-20.

Wattenbach, H. (2006). Farming Systems of the Syrian Arab Republic. FAO Project GCP/SYR/006/ITA, National Agricultural Policy Center, Damascus, p145. [online] available: http://www.napcsyr.org/dwnld-files/farming_systems/farming_system_tec_report_en.pdf. p.40.

Westlake, M. (2001). Strategic crops' sub-Sector. FAO Project GCP/SYR/006/ITA, National Agricultural Policy Centre (NAPC), Damascus, 84 pp., [online] available: http://www.napcsyr.org/dwnld-files/policy_studies/en/06_strategic_crops_en.pdf. p.2.

\section{Appendix I}

Due to the lack of census data at the individual farm level, we use secondary data from NAPC database (www.napcsyr.org) to perform farms' classification through the following process of disaggregation:

- The entire irrigated area of each region in DERAHA is divided according the administrative boundaries of their mantikas.

- $\quad$ The irrigated area in each mantika is divided according to the agro-ecological zones.

- The irrigated area in each mantika/agro-ecological zone combination is divided according to irrigation sources

- $\quad$ The irrigated area resulting from the last point is divided according to irrigation techniques.

Therefore, farm types are distinct according to their location (mantikas), agro-ecological zone (1-5), irrigation source (private wells, public networks, or rivers), and irrigation technique (flood, sprinkler, and drip).

An ad hoc survey is conducted to complete the data required for the models which are not available in any secondary source and to validate some of the data already present in some secondary sources to ensure validity and consistency. The survey data are collected from two sources: farmers and local experts (officials of local departments of agriculture in the relevant 
mantikas). All survey data used in the model to characterise the farm types are collected from the local experts unless stated otherwise. To complement some missing values, contacts with farmers are established with the assistance of the local experts though field visits or using phone calls. Each farm type is defined by a location, agro-ecological zone, irrigation source and irrigation technique; therefore, three farms are selected to represent each farm type. No detailed questionnaire is used to interview farmers, we rather use a checklist of questions depending on farm characteristics and the missing values.

The following paragraphs explain in detail all data used in the model together with their sources, whether from the survey or any secondary source.

\section{I.1. Farm fixed resources}

\section{I.1.1. Farm size and cropping patterns}

The definition of the average farm size for each farm type is determined by dividing the total cultivated area at the lowest level of disaggregation (the irrigation technique level) by the number of farms. Due to the absence of official data about the number of farms at this level, the estimates of the local experts are used. Then the total areas of the cultivated crops are divided by the number of farms to obtain the average cropping pattern of each farm type.

\section{I.1.2. Water availability}

Water availability at the farm type level is fully determined through the findings of the ad hoc survey. It depends on irrigation water sources. When the source of water is private wells, water availability is estimated based on the maximum capacity of the pump-sets that the farmers have. So water availability in each month is the same across the year since farmers have deep wells that guarantee stable water flow along the year.

When irrigation source is public nets, farmers' access to irrigation water is controlled by governmental agencies. In this case, water availability in each farm is estimated according to a pre-determined schedule set by the Ministry of Irrigation (MOI) in which every farmer has access to water for some time per week during certain months of the year. In cases where a river is the main source of irrigation, water availability is estimated in a similar way to that of public networks, since farmers using rivers for irrigation are organised in consortiums which work under the supervision of the MOI who sets a schedules for each consortium.

\section{I.1.3. Family labour availability}

Due to the absence of census data, family labour availability is assumed differently according to the local conditions observed during the survey through the assistance of local experts.

\section{I.1.4. Cash capital availability}

Cash availability is fully determined based on the findings of the study survey and farmers were asked directly about the amount of liquid capital available to finance agricultural operations at the beginning of the agricultural year, which was assumed to be November. However, due to the sensitivity of this question, we relied on experience of local experts, who have always been in contact with the interviewed farmers, to validate these data.

\section{I.1.5. Irrigation methods}




\section{$\triangle$ Macrothink}

Environmental Management and Sustainable Development 102102 ISSN 2164-7682 2013, Vol. 2, No. 1

The observed irrigation schemes are flood, sprinkler, and drip. These techniques are presented in the model using dummy variables taking values of zero or one. These dummies represent an 'investment switch' so they allow making simulations of switching farms from the flood scheme to drip or sprinkler techniques by changing the value of the variable from zero to one. In this regard, the model recognises that some irrigation techniques are not suitable for some crops, for example, drip scheme is not suited for irrigating wheat and barley. In addition, the model recognises the possibility of switching wheat and barley (but not cotton) to the rain-fed mode. This is because wheat and barley can be grown without irrigation, but giving lower yields, but it is impossible to grow cotton in Syria without irrigation. However, the model does not include the fixed costs associated with the investment switch since only variable costs are considered to be relevant for farmers' decisions.

\section{I.2. Technical coefficients}

\section{I.2.1. Irrigation water requirements}

The irrigation requirements of the various crops are determined at the agro-ecological zone level in each region by month. These requirements are drawn from data of GCASR (2006). However, these data are adjusted in light of the survey findings because farmers use more water for irrigation than indicated in the secondary source. The numbers indicated in the official source are calculated using some equations reflecting the 'optimal' irrigation requirements rather than the real ones, and they are only used as a reference point.

Irrigation requirements are different by region, agro-ecological zone, crop, irrigation techniques and month. The differences in irrigation requirements due to different irrigation techniques are based on assumptions drawn from the discussions with the local experts of agricultural departments. It is assumed that sprinkler and drip techniques save $10 \%$ and $20 \%$ with respect to the traditional flood technique, although the water saved using these two modern techniques are much higher in the 'optimal' situations.

\section{I.2.2. Labour requirements}

Labour requirements for each crop are mainly obtained from a secondary source at a monthly level (MAAR, 1994). However, the labour requirements for labour demanding operations (such as cotton and sugar beet harvesting) are modified in light of the survey findings to reflect the differences in yield among different farm types, since the numbers of the secondary source are averages at the national level. This is important because harvesting is the operation that requires most labour needed for cotton and sugar beet growing, and it is heavily affected by yield.

\section{I.2.3. Physical inputs}

These data include the crops' requirements of chemical fertilisers and seeds and they are obtained from the study survey. They are three kinds of chemical fertilisers used for all crops: nitrogen, phosphate, and potash. Their required quantities differ by crop for irrigated cultivation. If the crops are rainfed, they are then different according to the agro-ecological 
zones too, due to the differences in rainfall that affect crops' responses to fertilisation. These data are fully gathered during the survey from farmers.

\section{I.2.4. Crop yields}

Crop yields differ according to mantikas, agro-ecological zones, and irrigation methods for irrigated crops. These data are adopted from NAPC database but adjusted through the survey. However, due to the absence of secondary data on the yields of crops irrigated by drip and sprinkler schemes, their yields are estimated based on the discussion with the local experts and are crosschecked with some farmers' records on yields. It is assumed that sprinkler and drip techniques increase the yields by $10 \%$ and $15 \%$ respectively with regard to flood method. This takes into consideration that some techniques are not suited for some crops; for example, drip technique does not suite the irrigation of wheat and barley. In this case, yield is assumed equal to zero.

\section{I.3. Prices of inputs and outputs}

\section{I.3.1. Prices of outputs}

It is mentioned above that some crops have fixed prices, such as cotton and sugar beet. Therefore, their prices reported in the annual agricultural abstract of the MAAR are used. For crops that have floor prices, such as wheat, barley, lentil, and chickpea, we assume that their floor prices are the effective ones in the decision making process of farmers.

The choice of prices is not easy for crops whose prices are determined by the interactions of supply and demand without a direct intervention from the Government. This is very much true since these prices may change from year to year according to market conditions. Such variability in the prices is the only cause of variability of farms' incomes in our model, and caution is necessary in choosing the method to model them. In our case, we make an assumption on their statistical distribution. We assume that the variability of these prices has a lognormal distribution, which has several advantages for our case. First, such distribution can be represented by its first and second moments as the case of normal distribution; however, it has an advantage over the latter, since variables of lognormal distribution do not take negative values, which is important in our case since negative prices have no sense. Second, lognormal distribution is very consistent with price variability. On one hand, the values of the variable cannot take values less than zero, and it is very reasonable that prices may go very high if a sudden supply shock occurs on the other hand.

In line with this assumption, we generate a matrix of prices in which prices are specified by product and state of nature. We use the method of Gauss-Hermite quadrature as described in Kenneth \& Judd (1998) to create a price series for each product assuming the presence of ten states of nature, to which a specific probability is attached.

Then we randomized the price matrix according to the type of correlation existing between each pair of prices, so that prices of two crops increase together (in opposite directions) if positive (negative) correlation is observed. It is of interest to state that prices of strategic crops are constant regardless of the state of nature reflecting that their variance is equal to zero and their correlation with other prices is also equal to zero. 


\section{I.3.2. Prices of inputs}

The prices of all kinds of chemical fertilisers and seeds of cotton, wheat, sugar beet and barley, are set administratively by the GOS through the ACB. For the seed prices of other crops, we use data collected at the farm level.

\section{I.4. Labour wage}

Labour wage in Syria is paid in a non-standardised way. It might be paid on a daily basis as in the case of weeding or according to the performance as the case of cotton harvesting. In addition, the labour wage might be different according to the task whether it easy or hard. Nevertheless, for reasons of simplification, we use one standard labour wage per hour. This matter was discussed with the local experts as well as with the interviewed farmers. Based on that, we assume that labour wage was $25 \mathrm{SP} /$ hour in the reference year.

\section{I.5. Water costs}

Water costs are different according to water sources. Farms that depend on the public nets for irrigation pay an annual irrigation fee per hectare regardless of the amount of water used. Farms who depend on private wells and rivers do not pay any fee, but they incur pumping costs which might be considerable.

Pumping costs are calculated by the model by multiplying the diesel requirements per crop per hectare by diesel price, which is set centrally by the GOS, but in the model we use the effective price paid by farmers that includes the cost of transporting the diesel to the farm gate level. The diesel requirements are assumed to be different by crop, mantika, and agro-climatic zone, irrigation source and irrigation technique, and they are calculated based on the survey findings.

\section{I.6. Interest rate}

Concerning the interest rate, we consider only credit that covers the costs of variable inputs and agricultural operations, which lies under the short-term credit according to the loan categories of the Syrian Agricultural Bank (ACB), since our model takes into our consideration only cash operating costs. The ACB's interest rate for such credit differs according to whether the borrowers act individually or collectively. But due to lack of such data at the individual farm level, we assume a unique interest rate for all which is a weighted average of both previous ones. The assumed weighted average is based on personal judgements of local experts.

\section{I.7. Other costs}

\section{I.7.1. Rental machinery costs}

Many crops in DERAHA are highly mechanised. Wheat and barley are almost totally mechanised, where irrigation is the only manually performed operation. The situation is similar for cumin, chickpea, maize and lentil with the only exception that harvesting is performed both manually and mechanically. For cotton, machinery is used only for ploughing and tillage. 
Almost all farmers in DERAHA rent machinery to perform these operations due to the active market for these services caused by the presence of specialised agents providing them. Harvesting cost in DERAHA is paid on an output-percentage basis which is 5-6\% of the production value, while other machinery services are paid on a per-hectare basis. Data on rented machinery are totally obtained from the survey findings.

\section{I.7.2. Transportation and other costs}

These include the costs of transportation of the output (to the market or governmental delivery centres), costs of liquid chemicals, packing materials, cost of oil and repairs for the pumping sets, etc. These costs form a small proportion of the total variable costs, and they differ only according to the crop for irrigated farming, but also according to yields for rain-fed farming. These costs are calculated based on the survey findings and they are summed up in the model in one category.

\section{Copyright Disclaimer}

Copyright reserved by the author(s).

This article is an open-access article distributed under the terms and conditions of the Creative Commons Attribution license (http://creativecommons.org/licenses/by/3.0/). 